Original Article

Joumal of Epilepsy Research pISSN 2233-6249 / eISSN 2233-6257

Received May 14, 2021

Revised June 3, 2021

Accepted June 6, 2021

Corresponding author:

Ahmad Reza Dehpour, PharmD, PhD

Department of Pharmacology, School of

Medicine, Tehran University of Medical

Sciences, Poursina Street, Keshavarz Blvd,

Tehran 13145-784, Iran

Tel. +982188973652

Fax. +98 2166402569

E-mail; Dehpour@yahoo.com

\title{
Involvement of N-Methyl-D-Aspartate Receptors in the Anticonvulsive Effects of Licofelone on Pentylenetetrazole-Induced Clonic Seizure in Mice
}

\author{
Ramtin Gholizadeh, DVM ${ }^{1,2}$, Zohreh Abdolmaleki, $\mathrm{PhD}^{2}$, \\ Taraneh Bahremand, MSc, MPH, PharmD ${ }^{1,3}$, Mehdi Ghasemi, MD, MPH ${ }^{4}$, \\ Mehdi Gharghabi, PharmD ${ }^{5}$, Ahmad Reza Dehpour, PharmD, PhD ${ }^{1,3}$ \\ ${ }^{1}$ Department of Pharmacology, School of Medicine, Tehran University of Medical Sciences, Tehran; ${ }^{2}$ Department of \\ Pharmacology, College of Veterinary Medicine, Islamic Azad University, Karaj; ${ }^{3}$ Experimental Medicine Research \\ Center, Tehran University of Medical Sciences, Tehran, Iran; ${ }^{4}$ Department of Neurology, University of \\ Massachusetts Medical School, Worcester, MA; ${ }^{5}$ Department of Cancer Biology and Genetics, Comprehensive \\ Cancer Center, Ohio State University Wexner Medical Center, Columbus, OH, USA
}

\begin{abstract}
Background and Purpose: Licofelone is a dual 5-lipoxygenase/cyclooxygenase inhibitor, with well-documented anti-inflammatory and analgesic effects, which is used for treatment of osteoarthritis. Recent preclinical studies have also suggested neuroprotective and anti-oxidative properties of this drug in some neurological conditions such as seizure and epilepsy. We have recently demonstrated a role for nitric oxide (NO) signaling in the anti-epileptic activity of licofelone in two seizure models in rodents. Given the important role of $\mathrm{N}$-methyl-D-aspartate receptors (NMDARs) activation in the NO production and its function in the nervous system, in the present study, we further investigated the involvement of NMDAR in the effects of licofelone $(1,3,5,10$, and $20 \mathrm{mg} / \mathrm{kg}$, intraperitoneal [i.p.]) in an in vivo model of seizure in mice.
\end{abstract}

Methods: Clonic seizures were induced in male NMRI mice by intravenous administration of pentylenetetrazol (PTZ).

Results: Acute administration of licofelone exerted anticonvulsant effects at $10(p<0.01)$ and $20 \mathrm{mg} / \mathrm{kg}$ $(p<0.001)$. A combined treatment with sub-effective doses of the selective NMDAR antagonist MK-801 $(0.05 \mathrm{mg} / \mathrm{kg}$, i.p.) and licofelone (5 mg/kg, i.p.) significantly $(p<0.001)$ exerted an anticonvulsant effect on the PTZ-induced clonic seizures in mice. Notably, pre-treatment with the NMDAR co-agonist D-serine (30 $\mathrm{mg} / \mathrm{kg}$, i.p.) partially hindered the anticonvulsant effects of licofelone $(20 \mathrm{mg} / \mathrm{kg})$.

Conclusions: Our data suggest a possible role for the NMDAR in the anticonvulsant effects of licofelone on the clonic seizures induced by PTZ in mice. (2021;11:14-21)

Key words: Licofelone, Seizures, Pentylenetetrazole, N-methyl-D-aspartate receptor, Mice

\section{Introduction}

Licofelone, a substrate analogue of arachidonic acid, is a dual competitive inhibitor of 5-lipoxygenase (5-LOX), cyclooxygenase (COX)-1, and COX-2 that has been shown to be effective in the treatment of osteoarthritis. ${ }^{1}$ Additionally, licofelone exerts analgesic, anti-inflammatory, anti-pyretic, anti-bronchoconstrictive, and anti-platelet effects. ${ }^{2-4}$ In comparison to nonsteroidal anti-inflammatory drugs, licofelone contains a favorable gastrointestinal safety profile as well as promising efficacy in the treatment of osteoarthritis. ${ }^{1,5-7}$ Several stud- ies have also demonstrated effects of licofelone in decreasing the production of pro-inflammatory leukotrienes and prostaglandins. ${ }^{8-10}$ Given the fact that dysregulation of prostaglandins and leukotrienes can contribute to the pathophysiology of neurological disorders, ${ }^{11}$ effects of licofelone on various experimental models of central nervous system (CNS) disorders have been investigated suggesting neuroprotective and anti-oxidative effects for licofelone. ${ }^{12-14}$ Moreover, previous experiments have demonstrated modulatory effects of licofelone on neuroinflammatory markers in animal models of Alzheimer's disease. ${ }^{15}$ Furthermore, licofelone can exert antidepressant-like ef- 
fects probably due to its anti-inflammatory properties. ${ }^{16}$

Collectively, these studies point toward an instrumental therapeutic role of dual COX/5-LOX inhibitors in CNS disorders in which oxidative stress plays a key role. Consistent with this notion, the protective effect of licofelone in epileptic disorders has been investigated in recent years. ${ }^{17,18}$ For instance, inducible nitric oxide (NO) synthase inhibition could potentiate the anticonvulsive effects of licofelone on lithium-pilocarpine induced seizures in a rat model of status epilepticus (SE). ${ }^{17}$ These results have also been reproduced in a pentylenetetrazole (PTZ)-induced clonic seizure model in mice. ${ }^{18}$ Furthermore, another COX/LOX inhibitor, BW755C, has been found to be protective against kainite-induced epilepsy in a rat model. ${ }^{19}$ Tenidap, another COX/LOX inhibitor, conferred neuroprotection and prevented the epileptogenesis process in lithium pilocarpine-induced SE in male rats. ${ }^{20}$ These studies collectively indicate the effectiveness of COX/LOX inhibitors in the management of different types of seizure.

Excitatory amino acids play a critical role in producing and sustaining epileptic activity in both the mature and developing brain. ${ }^{21}$ Glutamatergic N-methyl-D-aspartate receptors (NMDARs) receptors have been implicated in epileptogenesis. The selective NMDAR antagonist MK-801 is anticonvulsant in several models of epilepsy in both adults and immature animals. ${ }^{21}$ In adults, an anticonvulsant effect has been shown in the kindling, ${ }^{22,23} \mathrm{PTZ}^{24,25}$ electroshock, ${ }^{22,25}$ lithium/pilocarpine, ${ }^{26,27}$ bicuculline, ${ }_{1}^{28}$ soman, ${ }^{29}$ and kainic acid models. ${ }^{30-32}$ Activation of NMDARs in the CNS is responsible for neuronal NO production through activation on the neuronal NO synthase enzyme. ${ }^{33,34}$ It has been well established that NMDRs/NO signaling modulates seizure threshold in a variety of seizure models. ${ }^{35-38}$ Additionally, from several mechanisms that potentially contribute to the anticonvulsant effects of licofelone, the NO pathway has drawn much attention. 17,18,39 These data may indicate the potential involvement of NMDAR in the anti-seizure activity of licofelone. Therefore, we aimed to answer this question in the present study, which not only does provide novel insight on the protective effect of licofelone in the PTZ-induced clonic seizure model in mice, but also suggests NMDAR as a possible mediator involved in seizure susceptibility.

\section{Methods}

\section{Animals}

Male NMRI mice, aged 6-8 weeks and weighing 22-30 g, were used in this study. The animals were placed in a temperature-controlled $\left(22 \pm 3^{\circ} \mathrm{C}\right)$ colony room on a 12 -hour light/12-hour dark cycle with adequate and free access to food and water. The behavioral experiments were conducted between 09:00 and 14:00. The groups consisted of eight animals and each animal was used only once. All procedures were carried out in accordance with institutional guidelines for animal care and use of laboratory animals published by national institutes of health and with the approval of the Ethics Committee on Animal Experiments of Tehran University of Medical Sciences (IR.IAU.K.REC. 1396.100).

\section{Drugs}

The following drugs were used in the present study: PTZ (Sigma, Gillingham, UK), MK-801 (Dizocilpine or MK-801 ([+]-5-methyl-10,11-dihydro-5H-dibenzo [a,d]cyclohepten-5, 10-imine maleate; Sigma), and D-serine ( $\beta$ hydroxyalanine, (R)-2-Amino-3-hydroxypropionic acid; Sigma). Licofelone ([2,2-dimethyl-6-(4-chloropheny-7-phenyl-2,3dihydro-1H pyrrazoline-5-yl] acetic acid) was a generous gift from a pharmaceutical company, Tofigh daru (Tehran, Iran). To induce clonic seizures, PTZ was infused intravenously $(0.5 \%$, i.v.) into the lateral tail vein of mice. All other drugs were administered intraperitoneally (i.p) and injections were in a volume of $10 \mathrm{~mL} / \mathrm{kg}$ of the body weight of the mice. PTZ, MK-801 and D-serine were dissolved in sterile normal saline solution $(0.9 \%)$. Licofelone was suspended in a $1 \%$ aqueous solution of tween 80. In experiments investigating the possible role of NMDARs in the licofelone effects, mice were administered MK-801 and D-serine or saline vehicle. The dosages and timing of administrations of drugs in the present study were based upon pilot experiments and our previous study. $36,37,40,41$

\section{PTZ-induced seizure threshold measurement}

The animals were placed in a transparent restrainer and a 30-gauge dental needle was inserted in the lateral tail vein. ${ }^{42}$ The correct needle placement in the tail vein was verified by the appearance of blood in the tubing. The needle was then secured to the tail by a narrow piece of adhesive tape. With mouse moving freely, the PTZ solution $(0.5 \%)$ was slowly infused into the tail vein at a constant rate of (1 mL/min) using an infusion pump (NE 1000; New Era Pump System, Inc., Farmingdale, NY, USA), which was connected to the dental needle by polyethylene tubing. Infusion was immediately halted when general clonus (forelimb clonus followed by full clonus of the body) was observed. The minimal dose of PTZ (mg/ $/ \mathrm{kg}$ of mice weight) needed to induce general clonus was recorded as an index of clonic seizure threshold. 


\section{Experiments}

In experiment 1, we evaluated effects of licofelone on PTZ-induced clonic seizure thresholds in mice. Different doses of licofelone $(1,3$, 5,10 , and $20 \mathrm{mg} / \mathrm{kg}$, i.p.) or its vehicle (control) were administrated 60 minutes prior to the determination of PTZ-induced clonic seizure thresholds. Prior to this, a time-course experiment was performed, which revealed maximal efficacy for licofelone at 60 minutes post drug injection. Control animals received the same volume of the vehicle ( $1 \%$ aqueous solution of tween 80 ) in all experiments. Based on this experiment, sub-effective dose of $5 \mathrm{mg} / \mathrm{kg}$ of licofelone was chosen for subsequent experiments.

In experiment 2, we examined the role of NMDARs in the seizure threshold modulation by licofelone. Mice received acute administration of a non-effective dose of the noncompetitive NMDAR antagonist MK-801 (0.05 mg/kg, i.p.) 15 minutes before licofelone (1, 5 , and $20 \mathrm{mg} / \mathrm{kg}$ ) and 75 minutes before PTZ in separate groups. The non-effective dose of MK-801 $(0.05 \mathrm{mg} / \mathrm{kg})$ and the time points of administration prior to PTZ were selected based on our previous studies and a pilot experiment. ${ }^{37,40,41}$

In experiment 3, we assessed effects of the NMDAR co-agonist D-serine (30 mg/kg, i.p.) alone or 15 minutes before either the sub-effective ( $5 \mathrm{mg} / \mathrm{kg}$ ) or effective $(20 \mathrm{mg} / \mathrm{kg}$ ) doses of licofelone and 75 minutes prior seizures induced by PTZ in mice. The doses of D-serine and the time points of administration prior to PTZ were selected based one a pilot experiment.

\section{Statistical analysis}

Clonic seizure thresholds were presented as the mean \pm standard error of mean in each experimental group. Data were analyzed by one-way analysis of variance (ANOVA) followed by Tukey's post-hoc test for multiple comparisons. In all experiments, a $p$-value $<0.05$ was regarded as significant.

\section{Results}

\section{Effect of licofelone on PTZ-induced seizure threshold}

The PTZ-induced seizure analysis was performed at several different time points $(30,45,60$, and 75 minutes) after the administration of licofelone (20 mg/kg) to identify the most effective time point to reach maximal anticonvulsant effect. Although licofelone exerted a significant anticonvulsant effect at all time points except 30 minutes, the highest anticonvulsant effect was observed 60 minutes after licofelone administration $(p<0.001)$ in comparison with the correspond-
A

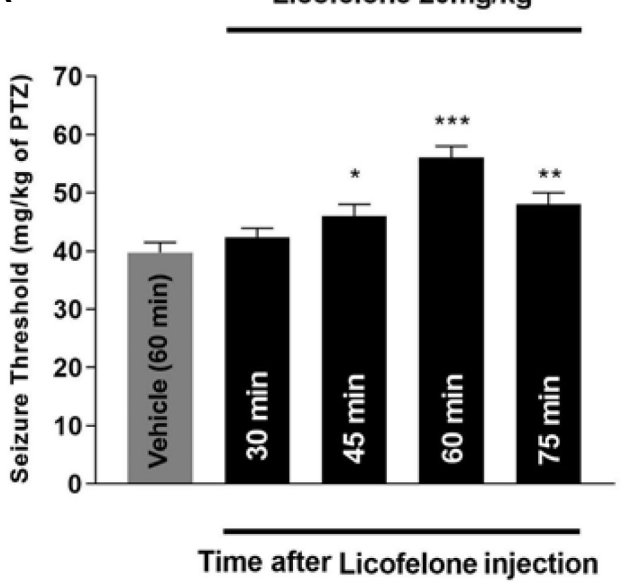

B

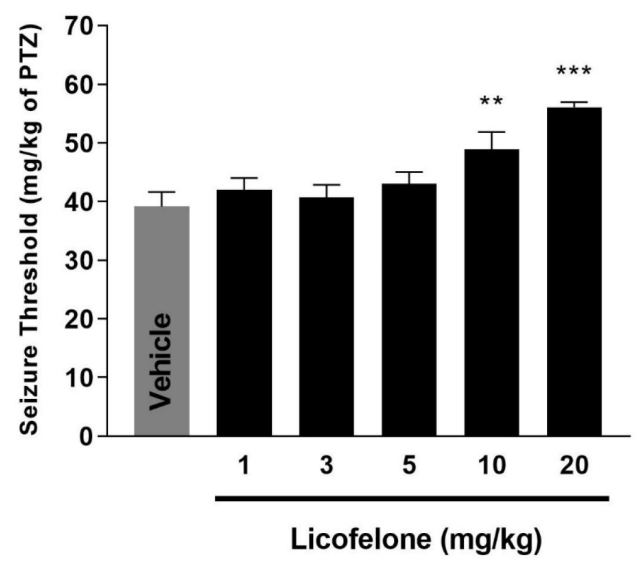

Figure 1. Effects of licofelone on PTZ-induced seizure threshold in mice. (A) Time course properties of licofelone potent dose (20 mg/kg) on the clonic seizure threshold induced by PTZ in mice. Licofelone was administered intraperitoneally (i.p.) 30, 45, 60, and 75 minutes before PTZ injection and the effects on the seizure threshold effects were compared to the vehicle control group (administered i.p. 60 minutes before the test). Data are expressed as mean \pm S.E.M. of seizure threshold in each group. Each group consisted of eight mice. ${ }^{*} p<0.05,{ }^{*} * p<0.01$, and ${ }^{* \star *} p<0.001$ compared with the control group. It should be considered that the control group was same as (A) and repeated here for better comparisons. (B) Different doses of licofelone (1, 3, 5, 10, and 20 mg/kg, i.p.) were injected 60 minutes prior to the determination of seizure threshold. Data are shown as the mean \pm S.E.M. of seizure threshold in each group. Each group consisted of eight mice. ${ }^{* *} p<0.01$ and ${ }^{* * *} p<0.001$ compared with the vehicle control group. There were no statistically significant differences between any of the other groups tested. PTZ, pentylenetetrazol; S.E.M., standard error of mean; i.p., intraperitoneal. 
ing vehicle-treated control animals (Fig. 1A). Subsequently, different doses of licofelone $(1,3,5,10$, and $20 \mathrm{mg} / \mathrm{kg})$ were administered 60 minutes prior to the PTZ-induced clonic seizures. One-way ANOVA followed by Tukey post-hocanalysis revealed a statistically significant effect for licofelone at $10 \mathrm{mg} / \mathrm{kg}(p<0.01)$ and $20 \mathrm{mg} / \mathrm{kg}(p<0.001)$ compared to the control group. Licofelone injections at the lower doses $(1,3$, and $5 \mathrm{mg} / \mathrm{kg})$ did not alter seizure thresholds, suggesting a dose dependent anti-convulsant effect for licofelone (Fig. 1B).

\section{Effects of MK-801 on the anticonvulsant effects of licofelone}

To investigate the effects of NMDARs on the clonic seizure thresholds, a non-effective dose of the NMDAR antagonist MK-801 (0.05 $\mathrm{mg} / \mathrm{kg}$, i.p.) were injected 15 minutes prior to different doses of licofelone $(1,5$, and $20 \mathrm{mg} / \mathrm{kg}$, i.p.) and 75 minutes prior to the PTZ-induced clonic seizure determination. As depicted in Figure 2,

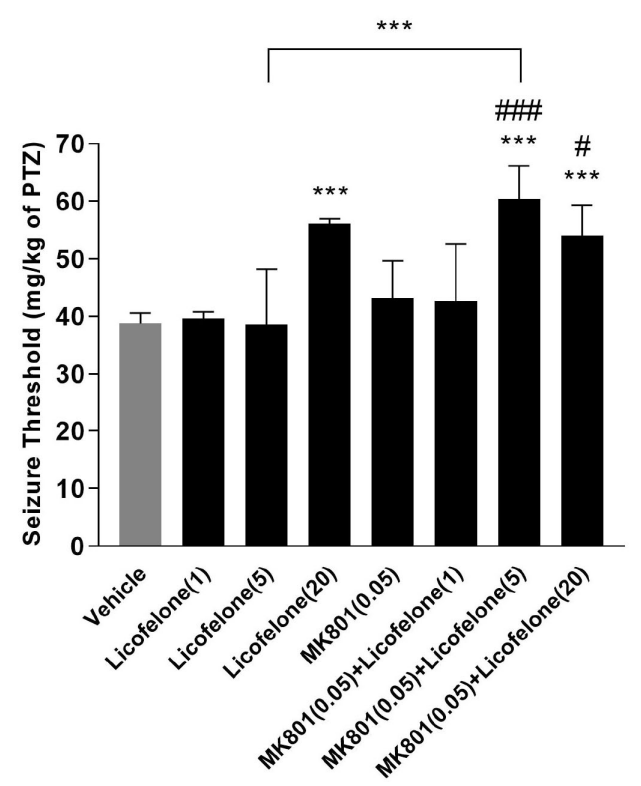

Figure 2. Effects of MK-801 on the effects of licofelone on PTZ-induced seizure threshold in mice. Licofelone (1, 5, and $20 \mathrm{mg} / \mathrm{kg}$, i.p.) was injected 60 minutes before the PTZ injection in different groups. In separate groups, low dose of MK-801 (0.05 mg/kg, i.p.) was also administrated 15 minutes before the non-effective doses of licofelone ( 1 and $5 \mathrm{mg} / \mathrm{kg}$ ) or 75 minutes before intravenous injection of PTZ. The data shows that MK-801 significantly potentiated the anticonvulsant effect of licofelone at its sub-effective dose $(5 \mathrm{mg} / \mathrm{kg}$ ). Data are shown as the mean \pm S.E.M. of seizure threshold in each group. Each experimental group consisted of eight mice. ${ }^{* *} p<0.001$ compared with the vehicle control group; ${ }^{\#} p<0.05$ and ${ }^{\# \#} p<0.001$ in comparison with the MK-801 (0.05 mg/kg) group. PTZ, pentylenetetrazol; S.E.M., standard error of mean; i.p., intraperitoneal. pre-treatment with the non-effective dose of MK-801 $(0.05 \mathrm{mg} / \mathrm{kg}$ i.p.) 15 minutes prior to non-effective dose of licofelone $(5 \mathrm{mg} / \mathrm{kg})$, exerted a significant anticonvulsant effect compared to the vehicle ( $p<0.001)$ and corresponding licofelone ( $5 \mathrm{mg} / \mathrm{kg}$ ) group ( $p<0.001)$. This finding indicates a possible role of NMDARs in the licofelone's effects on clonic seizure threshold in mice. Additionally, the comparisons between MK-801 $(0.05 \mathrm{mg} / \mathrm{kg})$ group and the combination groups of MK-801 $(0.05 \mathrm{mg} / \mathrm{kg})$ with different doses of licofelone (5 $\mathrm{mg} / \mathrm{kg}, 20 \mathrm{mg} / \mathrm{kg}$ ) were significant $(p<0.05$ and $p<0.001$, respectively). Interestingly, pre-treatment of MK-801 prior to the lower $1 \mathrm{mg} / \mathrm{kg}$ dose of licofelone did not result in a significant change in the seizure threshold, suggesting a dose-dependent effect (Fig. 2). There were no statistically significant differences between any of the other groups tested.

\section{Effect of D-serine on the anticonvulsant effects of licofelone}

As shown in Figure 3, D-serine alone at $30 \mathrm{mg} / \mathrm{kg}$ did not affect the clonic seizure thresholds. However, pre-treatment with this non-effective dose of D-serine (30 mg/kg, i.p.) 15 minutes prior to an

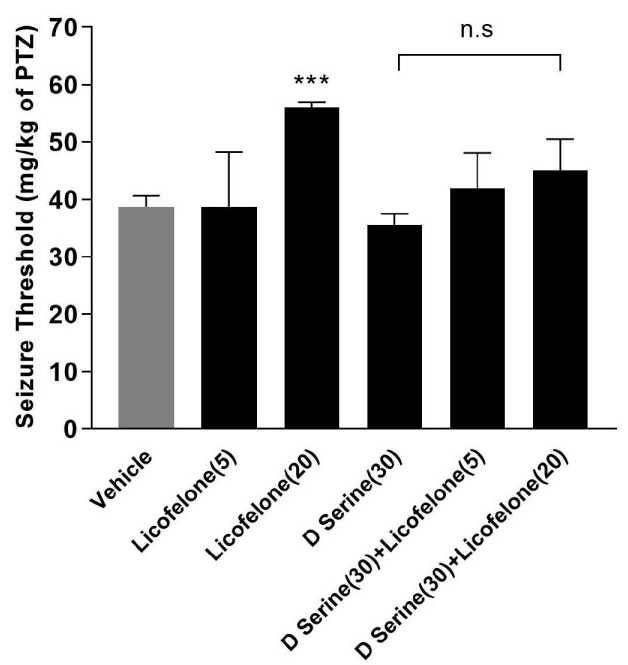

Figure 3. Effects of D-serine on the effects of licofelone on PTZ-induced seizure threshold in mice. Licofelone ( 5 and $20 \mathrm{mg} / \mathrm{kg}$ ) was injected 60 minutes before the PTZ injection in different groups. In separate groups, D-serine $(30 \mathrm{mg} / \mathrm{kg}$, i.p.) was also administered 15 minutes before licofelone ( 5 and $20 \mathrm{mg} / \mathrm{kg}$, i.p.) or 75 minutes prior the intravenous PTZ injection. Data are expressed as the mean \pm S.E.M. of seizure threshold in each group. Each group consisted of eight mice. ${ }^{* *} p<0.001$ compared with the vehicle control group. There were no statistically significant differences between any of the other groups tested. PTZ, pentylenetetrazol; n.s., non significant; S.E.M., standard error of mean; i.p., intraperitoneal. 
effective dose of licofelone (20 mg/ $\mathrm{kg}$ ) considerably hindered the anticonvulsant effects of licofelone treatment at $20 \mathrm{mg} / \mathrm{kg}(p>0.05)$. Pre-treatment of D-serine prior to the lower non-effective dose of licofelone $(5 \mathrm{mg} / \mathrm{kg}$ ) did not result in any significant changes in the seizure threshold (Fig. 3).

\section{Discussion}

Findings of the present study confirm the previously established anticonvulsant effects of the dual COX/5-LOX inhibitor licofelone in the PTZ-induced clonic seizure model in mice. We also found that inhibition of the NMDAR using the receptor antagonist MK-801 can potentiate the anti-seizure property of licofelone in a dose-dependent manner, while the NMDAR co-agonist D-serine considerably hinders the effects of licofelone on seizure threshold, indicating a possible role for NMDAR in this anticonvulsant properties of licofelone.

Licofelone, as a 5-LOX inhibitor, can act as a neuroprotective agent in a variety of CNS disorders. ${ }^{43}$ Consequently, much of the current literature on licofelone has drawn particular attention to its therapeutic role in neurological conditions, which may contribute to a novel therapeutic modality for the treatment of brain disorders such as Alzheimer's disease and epilepsy. 15,17,44 Findings concerning licofelone application in animal models of the Alzheimer's disease have depicted its modulatory effects on neuroinflammatory markers. ${ }^{15}$ Furthermore, licofelone has been shown to exert antidepressant-like effects probably through its anti-inflammatory property. ${ }^{16}$ In line with this, other COX inhibitors, either selective (nimesulide, rofecoxib and celecoxib) or non-selective (aspirin, naproxen), have been examined in animal seizure models, suggesting an elevation in the seizure threshold. ${ }^{45}$ In the present study, the effects of acute administration of five different doses of licofelone $(1,3,5,10$, and $20 \mathrm{mg} / \mathrm{kg}$, i.p.) were investigated which revealed that licofelone at doses higher than $10 \mathrm{mg} / \mathrm{kg}$ could significantly increase PTZ-induced seizure thresholds compared to vehicle. This is in accordance with recent reports as well as earlier findings in SE and PTZ-induced seizures, respectively. ${ }^{17,18,46}$ In the current study, licofelone exerted its maximum effect 60 minutes after administration, which is in accordance with other studies reporting the same onset of action. ${ }^{18}$ The anticonvulsant effects of licofelone observed in this study can be explained at least partly by inhibition of COX-2. Induction of COX-2 mRNA and protein following an electroconvulsive seizure has been reported in rat hippocampus and cerebral cortex, and the COX-2 expression in neurons is regulated by NMDA dependent synaptic activity. ${ }^{47}$ Inhibition of the NMDA pathway using MK801 has been shown to reduce the expression levels of COX-2 mRNA throughout the cerebral cortex. ${ }^{47}$

Furthermore, the key findings of the current study can be explained by the role of both NMDA receptors and COX in the permeability of the blood brain barrier (BBB) in neurological ailments. Disruption of the BBB has been associated with seizure induction in several human and rodent studies. ${ }^{48-52}$ On the one hand, activation of NMDA receptor by the excitatory neurotransmitter glutamate leads to BBB disruption and increased permeability in the human brain ${ }^{53}$ while NMDA inhibition by MK-801 prevents BBB breakdown in brain capillary endothelial cells. ${ }^{54}$ Our findings from the use of MK801 and D-serine can therefore be explained by their potential effect on BBB permeability, and consequently increased levels of epilepsy mediators in the brain, most importantly P-glycoprotein, which has been associated with triggering seizure activity in many studies. ${ }^{52,55-58}$ On the other hand, the expression levels of P-glycoprotein in the brain are increased during PTZ induced seizures which is associated with membrane depolarization in the hippocampus. ${ }^{59}$ This upregulation is most interestingly triggered by glutamate induced NMDA receptor activation which is also modulated by COX-2. ${ }^{60,61}$ Therefore, in our study, the anticonvulsant effects of the LOX/COX inhibitor licofelone and our observations from pre-treatments with an NMDA agonist and antagonist can potentially be explained by the important roles of both NMDA receptors and COX-2 in the expression levels of P-glycoprotein and the permeability of the BBB to this important epilepsy mediator. This hypothesis needs to be further investigated in future studies.

The pathophysiology of epileptic seizures is complex, and it is known that an array of signaling pathways is activated to provoke the process of epileptogenesis, among which activation of the AMPA, kainite, and NMDARs have been supposed to have a key role in neuronal excitability in seizures. ${ }^{39,62}$ Excessive activation of NMDARs has been suggested to contribute to the various neurologic disorders including brain damage associated with stroke and neurodegenerative illnesses. ${ }^{63-65}$ Accumulating evidence also suggest that NMDARs play a crucial role in modulating seizure threshold and brain excitability in various animal models of seizures, including PTZ-induced clonic and tonic-clonic seizures. ${ }^{38,66-69}$ and flurothyl-induced clonic and tonic-clonic seizures. ${ }^{70}$ Blocking or suppression of NMDARs with ketamine has been associated with lower seizure susceptibility in electroconvulsive therapy-induced seizures. ${ }^{71}$ Likewise, trials on human subjects revealed that NMDAR blockers including felbamate could 
potentially be developed as a treatment option in controlling refractory partial seizures. ${ }^{72,73}$ This anticonvulsant effect might also result from the proposed dual action of felbamate as a NMDAR blocker as well as activation of the GABAergic activity. ${ }^{73}$ Our data also showed that acute injection of the NMDAR antagonist MK-801 had anticonvulsant effects on seizure threshold, which was effective at $0.1 \mathrm{mg} / \mathrm{kg}$ and higher doses in our previous study. ${ }^{36,37}$ This observation further confirms the role of NMDARs in modulating seizure threshold. Considering these notions stated herein, we next attempted to test the possible involvement of NMDA pathway on seizure susceptibility by pre-treating the animals receiving licofelone with a noncompetitive NMDA receptor antagonist, MK-801, and explored if it could enhance the anticonvulsant effects of licofelone in our model. Further experiment showed that the enhancing effect of licofelone on clonic seizure threshold was partially reversed by the NMDAR co-agonist D-serine, providing additional evidence that the modulation of seizure modulation may be mediated by NMDAR pathway.

Collectively, our data suggest that that NMDAR pathway may play a role the anticonvulsant effects of licofelone in the PTZ model of clonic seizure in mice. It is noteworthy that in our experiments, although combined non-effective doses of MK-801 $(0.05 \mathrm{mg} / \mathrm{kg})$ and licofelone $(5 \mathrm{mg} / \mathrm{kg})$ exerted a significant anticonvulsant effect on the PTZ-induced clonic seizures in mice, when MK-801 was combined with lower dose of licofelone $(1 \mathrm{mg} / \mathrm{kg})$, such anticonvulsant effect was not observed. This may raise the possibility that such a low dose of licofelone (1 mg/ $\mathrm{kg}$ ) does not reach to the threshold that affects NMDRs signaling and thereby increasing seizure threshold combined with MK-801. The other possibility is that NMDARs may be only partially involved in such effects of licofelone on the PTZ-induced clonic seizure thresholds. Consistent with latter assumption, our data also showed that D-serine at $30 \mathrm{mg} / \mathrm{kg}$ only partially reversed the anticonvulsant effects of licofelone at $20 \mathrm{mg} / \mathrm{kg}$. Therefore, it is possible that NMDARs may have partially contributed to the anticonvulsant effects of licofelone on the PTZ-induced clonic seizures in mice. Considering the function of NMDAR and its role in epilepsy, further studies such as using the chronic epilepsy models (e.g., SE and recurrent seizures) are needed to verify the exact role of NMDAR in the anticonvulsant property of licofelone.

These behavioural results are prominent and could lay the groundwork to propose a novel mechanism for licofelone activity, which indeed mandates comprehensive molecular investigation in our upcoming investigations. Also, to introduce this drug class as a poten- tial anti-epileptic agent in the clinic, several questions concerning the safety of NMDAR antagonists need to be meticulously pursued in future studies.

\section{Conflict of Interest}

The authors declare that they have no conflicts of interest.

\section{References}

1. Cicero AF, Laghi L. Activity and potential role of licofelone in the management of osteoarthritis. Clin Interv Aging 2007;2:73-9.

2. Laufer S, Tries S, Augustin J, Dannhardt G. Pharmacological profile of a new pyrrolizine derivative inhibiting the enzymes cyclo-oxygenase and 5-lipoxygenase. Arzneimittelforschung 1994;44:629-36.

3. Laufer $\mathrm{S}$, Tries $\mathrm{S}$, Augustin J, et al. Acute and chronic anti-inflammatory properties of [2,2-dimethyl-6-(4-chlorophenyl)-7-phenyl-2, 3-dihydro-1H-pyrrolizine-5-yl]-acetic acid. Arzneimittelforschung 1995;45:27-32.

4. Laufer $S$, Tries $S$, Augustin J, et al. Gastrointestinal tolerance of [2,2-dimethyl-6-(4-chlorophenyl-7-phenyl-2,3-dihydro-1H-pyrrolizine-5-yl]-acetic acid in the rat. Arzneimittelforschung 1994;44:1329-33.

5. Alvaro-Gracia JM. Licofelone--clinical update on a novel LOXJCOX inhibitor for the treatment of osteoarthritis. Rheumatology (Oxford) 2004;43 Suppl 1:i21-5.

6. Koeberle A, Werz O. Microsomal prostaglandin E2 synthase-1. In: Levin JI, Laufer S, ed. Anti-Inflammatory Drug Discovery. 1st ed. London: Royal Society of Chemistry, 2012;7-34.

7. Raynauld JP, Martel-Pelletier J, Bias P, et al. Protective effects of licofelone, a 5-lipoxygenase and cyclo-oxygenase inhibitor, versus naproxen on cartilage loss in knee osteoarthritis: a first multicentre clinical trial using quantitative MRI. Ann Rheum Dis 2009;68:938-47.

8. Tries $S$, Laufer $S$. The pharmacological profile of ML3000: a new pyrrolizine derivative inhibiting the enzymes cyclo-oxygenase and 5-lipoxygenase. Inflammopharmacology 2001;9:113-24.

9. Tries $S$, Neupert $W$, Laufer $S$. The mechanism of action of the new antiinflammatory compound ML3000: inhibition of 5-LOX and COX-1/2. Inflamm Res 2002;51:135-43.

10. Wallace JL, Carter L, McKnight W, Tries S, Laufer S. ML 3000 reduces gastric prostaglandin synthesis without causing mucosal injury. Eur J Pharmacol 1994;271:525-31.

11. Auriel E, Regev K, Korczyn AD. Nonsteroidal anti-inflammatory drugs exposure and the central nervous system. Handb Clin Neurol 2014; 119:577-84.

12. Bishnoi M, Patii CS, Kumar A, Kulkarni SK. Relative role of cyclooxygenase-2 (COX-2) inhibitors and lipoxygenase (LOX) inhibitors in aging induced dementia and oxidative damage. Ann Neurosci 2010;12:6-11.

13. Dulin JN, Karoly ED, Wang Y, Strobel HW, Grill RJ. Licofelone modulates neuroinflammation and attenuates mechanical hypersensitivity in the chronic phase of spinal cord injury. J Neurosci 2013;33:652-64. 
14. Kalonia $H$, Kumar $P$, Kumar A. Licofelone attenuates quinolinic acid induced Huntington like symptoms: possible behavioral, biochemical and cellular alterations. Prog Neuropsychopharmacol Biol Psychiatry 2011;35: 607-15.

15. Kumar A, Sharma S, Prashar A, Deshmukh R. Effect of licofelone--a dual COX/5-LOX inhibitor in intracerebroventricular streptozotocin-induced behavioral and biochemical abnormalities in rats. J Mol Neurosci 2015; 55:749-59.

16. Mousavi SE, Saberi P, Ghasemkhani N, Fakhraei N, Mokhtari R, Dehpour AR. Licofelone attenuates LPS-induced depressive-like behavior in mice: a possible role for nitric oxide. J Pharm Pharm Sci 2018;21:184-94.

17. Eslami SM, Moradi MM, Ghasemi M, Dehpour AR. Anticonvulsive effects of licofelone on status epilepticus induced by lithium-pilocarpine in wistar rats: a role for inducible nitric Oxide synthase. J Epilepsy Res 2016;6:51-8.

18. Payandemehr B, Khoshneviszadeh M, Varastehmoradi B, et al. A COX/5-LOX inhibitor licofelone revealed anticonvulsant properties through iNOS diminution in mice. Neurochem Res 2015;40:1819-28.

19. Baran $H$, Vass $K$, Lassmann $H$, Hornykiewicz 0 . The cyclooxygenase and lipoxygenase inhibitor BW755C protects rats against kainic acid-induced seizures and neurotoxicity. Brain Res 1994;646:201-6.

20. Dhir A. An update of cyclooxygenase (COX)-inhibitors in epilepsy disorders. Expert Opin Investig Drugs 2019;28:191-205.

21. Ghasemi M, Schachter SC. The NMDA receptor complex as a therapeutic target in epilepsy: a review. Epilepsy Behav 2011;22:617-40.

22. McNamara JO, Russell RD, Rigsbee L, Bonhaus DW. Anticonvulsant and antiepileptogenic actions of MK-801 in the kindling and electroshock models. Neuropharmacology 1988;27:563-8.

23. Mintz M, Rose IC, Herberg $\amalg$. The effect of the NMDA receptor antagonist, MK-801, on the course and outcome of kindling. Pharmacol Biochem Behav 1990;35:815-21.

24. O'Neill SK, Bolger GT. Anticonvulsant activity of MK-801 and nimodipine alone and in combination against pentylenetetrazole and strychnine. Pharmacol Biochem Behav 1989;32:595-600.

25. Tricklebank MD, Singh L, Oles RJ, Preston C, Iversen SD. The behavioural effects of MK-801: a comparison with antagonists acting non-competitively and competitively at the NMDA receptor. Eur J Pharmaco/ 1989; 167:127-35.

26. Ormandy GC, Jope RS, Snead OC 3rd. Anticonvulsant actions of MK-801 on the lithium-pilocarpine model of status epilepticus in rats. Exp Neurol 1989; 106:172-80.

27. Walton NY, Treiman DM. Motor and electroencephalographic response of refractory experimental status epilepticus in rats to treatment with MK-801, diazepam, or MK-801 plus diazepam. Brain Res 1991;553:97-104.

28. Clineschmidt BV, Martin GE, Bunting PR. Anticonvulsant activity of (+)-5methyl-10, 11-dihydro-5Hdibenzo [a, d] cyclohepten-5, 10-imine (MK-801), a substance with potent anticonvulsant, central sympathomimetic, and apparent anxiolytic properties. Drug Dev Res 1982;2:123-34.

29. Sparenborg S, Brennecke LH, Jaax NK, Braitman DJ. Dizocilpine (MK-801) arrests status epilepticus and prevents brain damage induced by soman.
Neuropharmacology 1992;31:357-68.

30. Berg M, Bruhn T, Johansen FF, Diemer NH. Kainic acid-induced seizures and brain damage in the rat: different effects of NMDA- and AMPA receptor antagonists. Pharmacol Toxicol 1993;73:262-8.

31. Fariello RG, Golden GT, Smith GG, Reyes PF. Potentiation of kainic acid epileptogenicity and sparing from neuronal damage by an NMDA receptor antagonist. Epilepsy Res 1989;3:206-13.

32. Lees GJ. Effects of anaesthetics, anticonvulsants and glutamate antagonists on kainic acid-induced local and distal neuronal loss. J Neurol Sci 1992;108:221-8.

33. Ghasemi M, Claunch J, Niu K. Pathologic role of nitrergic neurotransmission in mood disorders. Prog Neurobiol 2019;173:54-87.

34. Ghasemi M, Fatemi A. Pathologic role of glial nitric oxide in adult and pediatric neuroinflammatory diseases. Neurosci Biobehav Rev 2014;45: 168-82.

35. Faghir-Ghanesefat $H$, Keshavarz-Bahaghighat $H$, Rajai $N$, et al. The possible role of nitric oxide pathway in pentylenetetrazole preconditioning against seizure in mice. J Mol Neurosci 2019;67:477-83.

36. Ghasemi M, Shafaroodi $H$, Nazarbeiki $S$, et al. Inhibition of NMDA receptor/NO signaling blocked tolerance to the anticonvulsant effect of morphine on pentylenetetrazole-induced seizures in mice. Epilepsy Res 2010;91:39-48.

37. Ghasemi M, Shafaroodi H, Nazarbeiki S, et al. Voltage-dependent calcium channel and NMDA receptor antagonists augment anticonvulsant effects of lithium chloride on pentylenetetrazole-induced clonic seizures in mice. Epilepsy Behav 2010;18:171-8.

38. Gholipour T, Ghasemi M, Riazi K, Ghaffarpour M, Dehpour AR. Seizure susceptibility alteration through $5-\mathrm{HT}(3)$ receptor: modulation by nitric oxide. Seizure 2010;19:17-22.

39. Panigrahi S, Li DD, Surai S, Ghosh A, Hong H. 5-lipoxygenase: emerging therapeutic targets in central nervous system disorders. Int I Adv Res Biol Sci 2018;5:20-9.

40. Homayoun $H$, Khavandgar S, Dehpour AR. The involvement of endogenous opioids and nitricoxidergic pathway in the anticonvulsant effects of foot-shock stress in mice. Epilepsy Res 2002;49:131-42.

41. Payandemehr $B$, Rahimian R, Bahremand A, et al. Role of nitric oxide in additive anticonvulsant effects of agmatine and morphine. Physiol Behav 2013;118:52-7.

42. Löscher W. Animal models of epilepsy for the development of antiepileptogenic and disease-modifying drugs. A comparison of the pharmacology of kindling and post-status epilepticus models of temporal lobe epilepsy. Epilepsy Res 2002;50:105-23.

43. Kulkarni S, Singh VP. Licofelone-A novel analgesic and anti-inflammatory agent. Curr Top Med Chem 2007;7:251-63.

44. Phillis JW, Horrocks LA, Farooqui AA. Cyclooxygenases, lipoxygenases, and epoxygenases in CNS: their role and involvement in neurological disorders. Brain Res Rev 2006;52:201-43.

45. Dhir A, Naidu PS, Kulkarni SK. Effect of cyclooxygenase inhibitors on pentylenetetrazol (PTZ)-induced convulsions: possible mechanism of 
action. Prog Neuropsychopharmacol Biol Psychiatry 2006;30:1478-85.

46. Sokola BS. Dual LOX/COX inhibition: a novel strategy to prevent neurovascular leakage in epilepsy [master's thesis]. [Lexington (KY)]: University of Kentucky; 2018.

47. Yamagata K, Andreasson Kl, Kaufmann WE, Barnes CA, Worley PF. Expression of a mitogen-inducible cyclooxygenase in brain neurons: regulation by synaptic activity and glucocorticoids. Neuron 1993;11:371-86.

48. Marchi N, Angelov L, Masaryk T, et al. Seizure-promoting effect of blood-brain barrier disruption. Epilepsia 2007;48:732-42.

49. Roch C, Leroy C, Nehlig A, Namer IJ. Magnetic resonance imaging in the study of the lithium-pilocarpine model of temporal lobe epilepsy in adult rats. Epilepsia 2002;43:325-35.

50. Seiffert $E$, Dreier JP, Ivens $S$, et al. Lasting blood-brain barrier disruption induces epileptic focus in the rat somatosensory cortex. J Neurosci 2004; 24:7829-36.

51. Tomkins O, Shelef I, Kaizerman I, et al. Blood-brain barrier disruption in post-traumatic epilepsy. J Neurol Neurosurg Psychiatry 2008;79:774-7.

52. van Vliet EA, da Costa Araújo S, Redeker $S$, van Schaik R, Aronica E, Gorter JA. Blood-brain barrier leakage may lead to progression of temporal lobe epilepsy. Brain 2007;130(Pt 2):521-34.

53. Collard CD, Park KA, Montalto MC, et al. Neutrophil-derived glutamate regulates vascular endothelial barrier function. J Biol Chem 2002;277: 14801-11.

54. Koenig H, Trout JJ, Goldstone AD, Lu CY. Capillary NMDA receptors regulate blood-brain barrier function and breakdown. Brain Res 1992;588: 297-303.

55. Hartz AM, Pekcec A, Soldner EL, Zhong Y, Schlichtiger J, Bauer B. P-gp protein expression and transport activity in rodent seizure models and human epilepsy. Mol Pharm 2017;14:999-1011.

56. Rizzi M, Caccia S, Guiso G, et al. Limbic seizures induce P-glycoprotein in rodent brain: functional implications for pharmacoresistance. J Neurosci 2002;22:5833-9.

57. Seegers $U$, Potschka $H$, Löscher W. Expression of the multidrug transporter P-glycoprotein in brain capillary endothelial cells and brain parenchyma of amygdala-kindled rats. Epilepsia 2002;43:675-84.

58. van Vliet $E$, Aronica $E$, Redeker $S$, et al. Selective and persistent upregulation of mdr1b mRNA and P-glycoprotein in the parahippocampal cortex of chronic epileptic rats. Epilepsy Res 2004;60:203-13.

59. Auzmendi JA, Orozco-Suárez S, Bañuelos-Cabrera I, et al. P-glycoprotein contributes to cell membrane depolarization of hippocampus and neocortex in a model of repetitive seizures induced by pentylenetetrazole in rats. Curr Pharm Des 2013;19:6732-8.
60. Bauer B, Hartz AM, Pekcec A, Toellner K, Miller DS, Potschka H. Seizure-induced up-regulation of P-glycoprotein at the blood-brain barrier through glutamate and cyclooxygenase-2 signaling. Mol Pharmacol 2008;73:1444-53.

61. Zibell G, Unkrüer $B$, Pekcec $A$, et al. Prevention of seizure-induced up-regulation of endothelial P-glycoprotein by COX-2 inhibition. Neuropharmacology 2009;56:849-55.

62. Zeng $H$, Liu $X$, Dou $S$, et al. Huang-Lian-Jie-Du-Tang exerts anti-inflammatory effects in rats through inhibition of nitric oxide production and eicosanoid biosynthesis via the lipoxygenase pathway. I Pharm Pharmacol 2009:61:1699-707.

63. Kalia LV, Kalia SK, Salter MW. NMDA receptors in clinical neurology: excitatory times ahead. Lancet Neurol 2008;7:742-55.

64. Rothman SM, Olney JW. Excitotoxity and the NMDA receptor. Trends Neurosci 1987;10:299-302.

65. Waxman EA, Lynch DR. N-methyl-D-aspartate receptor subtypes: multiple roles in excitotoxicity and neurological disease. Neuroscientist 2005;11: 37-49.

66. Ahmed MM, Arif M, Chikuma T, Kato T. Pentylenetetrazol-induced seizures affect the levels of prolyl oligopeptidase, thimet oligopeptidase and glial proteins in rat brain regions, and attenuation by MK-801 pretreatment. Neurochem Int 2005;47:248-59.

67. Croucher MJ, Collins JF, Meldrum BS. Anticonvulsant action of excitatory amino acid antagonists. Science 1988;216:899-901.

68. Gmiro V, Serdyuk S. Combined blockade of AMPA and NMDA receptors in the brain of rats prevents pentylenetetrazole-induced clonic and tonic-clonic seizures without ataxia. Bull Exp Biol Med 2008;145:728-30.

69. Mareš $P$, Mikulecká A. Different effects of two N-methyl-D-aspartate receptor antagonists on seizures, spontaneous behavior, and motor performance in immature rats. Epilepsy Behav 2009;14:32-9.

70. Velišsek L, Velísková J, Ptachewich Y, Shinnar S, Moshé SL. Effects of MK-801 and phenytoin on flurothyl-induced seizures during development. Epilepsia 1995;36:179-85.

71. Krystal $A D$, Weiner $R D$, Dean $M D$, et al. Comparison of seizure duration, ictal EEG, and cognitive effects of ketamine and methohexital anesthesia with ECT. I Neuropsychiatry Clin Neurosci 2003;15:27-34.

72. Faught $E$, Sachdeo RC, Remler MP, et al. Felbamate monotherapy for partial-onset seizures: an active-control trial. Neurology 1993;43:688-92.

73. Shi LL, Dong J, Ni H, Geng J, Wu T. Felbamate as an add-on therapy for refractory partial epilepsy. Cochrane Database Syst Rev 2017;7: CD008295. 